\title{
Fouad Laroui, La malédiction de l'écrivain maghrébin
}

\author{
Ilaria Vitali
}

\section{(2) OpenEdition}

\section{Journals}

\section{Edizione digitale}

URL: http://journals.openedition.org/studifrancesi/6453

DOI: 10.4000/studifrancesi.6453

ISSN: 2427-5856

\section{Editore}

Rosenberg \& Sellier

\section{Edizione cartacea}

Data di pubblicazione: 1 novembre 2010

Paginazione: 596-597

ISSN: 0039-2944

\section{Notizia bibliografica digitale}

|laria Vitali, «Fouad Laroui, La malédiction de l'écrivain maghrébin», Studi Francesi [Online], 162 (LIV | III) |

2010, online dal 30 novembre 2015, consultato il 14 janvier 2021. URL: http://

journals.openedition.org/studifrancesi/6453 ; DOI: https://doi.org/10.4000/studifrancesi.6453

Questo documento è stato generato automaticamente il 14 janvier 2021.

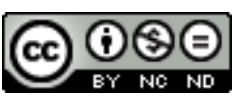

Studi Francesi è distribuita con Licenza Creative Commons Attribuzione - Non commerciale - Non opere derivate 4.0 Internazionale. 


\title{
Fouad Laroui, La malédiction de l'écrivain maghrébin
}

\author{
Ilaria Vitali
}

\section{NOTIZIA}

FOUAD LAROUI, La malédiction de l'écrivain maghrébin, «Nouvelles Études Francophones», vol. 24, n. 1, primavera 2009, pp. 124-128.

1 È una bella riflessione sul complesso rapporto tra scrittura, lingua e identità quella che propone in questo breve articolo lo scrittore marocchino Fouad Laroui. Il testo si apre con la definizione delle componenti che determinano l'opera letteraria: langue, style, codes. Partendo da questa prima enunciazione di stampo barthiano, l'autore innesta la riflessione nel campo della letteratura maghrebina, considerata fortemente problematica, a cominciare dalla scelta della lingua di scrittura: «Une fois cet arrièreplan posé, l'écrivain maghrébin ne peut qu'envier ses collègues européens ou américains, peut-être même ses collègues du monde entier. Eux, ils savent à quoi s'en tenir» (p. 124). L'autore evoca in primo luogo il fenomeno ben conosciuto della diglossia tra arabo classico e arabo dialettale, che impedisce, secondo Laroui, lo sviluppo di una letteratura araba moderna. Altro problema non meno importante è quello del lettorato: chi scrive in arabo, lo fa per un'élite e anche autori importanti come Naguib Mahfouz sono più conosciuti che letti (p.127): la tiratura delle loro opere in lingua araba non supera le diecimila copie. Poche, se confrontate ad un lettorato potenziale che conta oltre duecento milioni di persone. Al fenomeno della diglossia tra arabo classico e varianti dialettali si aggiunge poi il berbero, lingua essenzialmente orale, codificata, grazie all'azione dell'Institut Royal de la Culture Amazigh, solo in tempi recenti. Ecco perché molti autori maghrebini, sia arabi che berberi, hanno scelto - e continuano a scegliere - il francese, lingua "altra», non meno problematica per via dell'arrière-scène legato all'esperienza coloniale. Quella francofona maghrebina è una letteratura caratterizzata spesso da una sperimentazione formale giudicata a tratti eccessiva e condannata da molti critici a morte certa. Eppure, questa letteratura non fa che 
evolversi e arricchirsi ogni anno di nuovi autori. «Cela fait plus d'un demi-siècle qu'on annonce la fin de la littérature maghrébine d'expression française: elle n'a jamais été si foisonnante!» (p. 127).

2 Tuttavia, i problemi legati all'identità permangono, al punto da diventare la cifra stilistica di molti autori. In bilico tra lingue, registri, codici, lo scrittore maghrebino finisce per non sapere, secondo Laroui, chi è davvero. È questa la «maledizione» evocata nel titolo, che colpisce, a gradi diversi, ogni autore proveniente dal Maghreb. «Finalement, je vais faire acteur, c'est plus facile». (p. 128) Con queste parole ironiche ma quanto mai rivelatrici, prese in prestito ad un altro scrittore marocchino, Rachid 0 . Laroui chiude la sua riflessione sulla letteratura maghrebina all'inizio di questo nuovo millennio. Una letteratura «maledetta», fortemente problematica, ma che cela forse proprio in questa sua complessità e irrisolutezza la sua grande forza. 